\title{
Differences in expenditure and amounts of fresh foods, fruits and vegetables, and fish purchased in urban and rural Scotland
}

\author{
Baukje de Roos*, Ferdinando Binacchi, Stephen Whybrow and Alan A Sneddon \\ Rowett Institute of Nutrition \& Health, University of Aberdeen, Foresterhill, Aberdeen AB25 2ZD, UK
}

Submitted 5 April 2016: Final revision received 28 July 2016: Accepted 30 August 2016: First published online 5 October 2016

\begin{abstract}
Objective: To quantitatively analyse expenditure on all fresh foods, fruits and vegetables (F\&V) and fish across urban and rural households in Scotland. Fresh foods were chosen since, in general, they are perceived to contribute more to health than processed foods.

Design: Descriptive analysis of purchase data of all foods brought into the home during 2012 from the Kantar Worldpanel database. Purchase data were restricted to fresh, unprocessed and raw foods or 'fresh to frozen' foods where freezing was part of harvesting. Total household purchases were adjusted for household size and composition.

Setting: Scotland.

Subjects: Households ( $n$ 2576).

Results: Rural households reported the highest expenditure per person on fresh foods and $\mathrm{F} \& \mathrm{~V}$, but also bought the most (kilograms) of these items. There were linear trends of average prices paid with urban-rural location $(P<0.001)$, with average prices paid by large urban and remote rural households being $£ 2 \cdot 14 / \mathrm{kg}$ and $22 \cdot 04 / \mathrm{kg}$ for fresh foods, £1.64/kg and $1 \cdot 60 / \mathrm{kg}$ for F\&V and $£ 10 \cdot 07 / \mathrm{kg}$ and $£ 10 \cdot 20 / \mathrm{kg}$ for fish, respectively, although differences were quantitatively small.

Conclusions: Contrary to previous studies, purchase data show that access to and average prices of fresh foods generally, and F\&V and fish specifically, are broadly similar between urban and rural areas. Therefore, the higher expenditure on these foods in rural $v$. urban areas is probably due to factors other than pricing and availability.
\end{abstract}

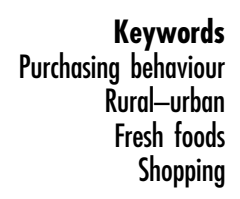

A recent report concluded that households in remote rural Scotland require higher incomes to attain the same minimum acceptable living standard as those living elsewhere in the $\mathrm{UK}^{(1)}$. This was, in part, due to the higher cost of certain types of products and services including food. In support of this, Dawson et al. ${ }^{(2)}$ reported that the average price of a basket of thirty-five 'healthy' products including fruits, vegetables, low-fat dairy products, and highcarbohydrate and high-protein items across Scotland was highest in rural compared with urban areas. Higher purchase costs are often reported as a perceived barrier to adopting healthier diets ${ }^{(3)}$. Healthier diets do tend to be more expensive than less healthy diets ${ }^{(4)}$, partly because fresh fruits and vegetables $(\mathrm{F} \& \mathrm{~V})$, which comprise a large component of a healthy diet, are expensive compared with energy-dense, highly processed foods ${ }^{(5)}$.

In addition, the availability of healthy foods may be fundamental to adopting healthier diets by consumer groups. The term 'food deserts' refers to areas of the country where consumers have limited access to healthier food choices ${ }^{(6)}$. Although their existence in the UK has been disputed, spatial variations in access to healthy foods in terms of availability of products as well as price do exist $^{(2)}$. This appears to be especially true for rural areas, where the absence of retail provision can create significant difficulties for consumers to access healthy foods. In rural areas, the distance that householders have to travel for food retail shopping is greater than in urban areas ${ }^{(7)}$; therefore, most rural households use their closest major supermarket to shop once weekly or once monthly, whereas local convenience stores and small shops are often considered a source of secondary shopping ${ }^{(8)}$. However, access to supermarkets does generally improve the availability of healthy foods, in addition to lowering prices $^{(6,9)}$.

Fresh foods are defined as those that have not undergone any processing and are therefore in their raw state. Assessing access to and average prices of fresh foods is important considering that they are perceived as a healthier option compared with processed or preserved foods 
for a number of reasons. These include lower salt levels and potentially higher nutrient levels. Indeed, processed red meats may contain up to four times more salt than fresh meats ${ }^{(10)}$, perhaps explaining why fresh meat consumption has a low correlation with the incidence of CVD whereas consumption of processed meat is positively linked to $\mathrm{CVD}^{(11)}$. In addition, consumption of fresh and frozen F\&V is linked to reduced risk of mortality, CVD ${ }^{(12)}$ and cancers of the pharynx, lung, mouth, stomach and oesophagus $^{(13)}$. Also, consumption of fish products and the marine fatty acids EPA and DHA is associated with a lower risk of $\mathrm{CVD}^{(14)}$.

In the present study, therefore, we examined whether there are differences in expenditure on fresh food products generally, or on F\&V and fish specifically, between urban and rural areas of Scotland. Note that, in defining fresh foods, some 'fresh to frozen' foods were also included where freezing was considered an essential part of harvesting and where the nutritional quality of these foods is considered similar to the unfrozen equivalent. Furthermore, we investigated whether purchasing behaviour differed according to outlet type or differences in household income or other socio-economic factors across regions.

\section{Methods}

Data from Kantar Worldpanel (KWP; www.kantarworld panel.com/en) were used for the present investigation. The KWP includes about 3000 households in Scotland, who report food and drink purchases brought into the home. Purchases that were reported between 26 December 2011 and 23 December 2012 (364 d) were included in the analyses. Information recorded on products included barcode data, purchaser (household) code, store and product price. Data on non-barcoded items such as fresh foods were collected using barcoded show cards (photographs) and questions. Data were not included for foods consumed outside the home (such as dining out), home-grown food and food items received as gifts. UK census data and the Broadcasters' Audience Research Panel Establishment Survey were used to define and predict demographic targets and to monitor the national representativeness of KWP. Compliance with scanning was encouraged by frequent postal, email or telephone reminders.

For each household, data on household composition, income band (sum of family income before tax), urbanrural classification (UR6) and degree of the area's deprivation using the Scottish Index of Multiple Deprivation (SIMD) were available, with the latter two based on the households' postcodes. The present investigation focused on entries from all Scottish households of the KWP for which an urban-rural classification was available (2576 households and 6733 people, adults plus children). Only purchases of fresh food items, which included fresh fruits, vegetables (including pre-packed salads), eggs, meats and
Table 1 Scottish Government's 6-Fold Urban-Rural Classification

\begin{tabular}{|c|c|}
\hline Designation & Definition \\
\hline $\begin{array}{l}\text { UR6 1: Large urban } \\
\text { areas }\end{array}$ & Settlements of $>125000$ people \\
\hline $\begin{array}{l}\text { UR6 2: Other urban } \\
\text { areas }\end{array}$ & Settlements of $10000-125000$ people \\
\hline $\begin{array}{l}\text { UR6 3: Accessible } \\
\text { small towns }\end{array}$ & $\begin{array}{l}\text { Settlements of } 3000-10000 \text { people; } \\
<30 \text { min drive to a settlement of } \\
>10000 \text { people }\end{array}$ \\
\hline $\begin{array}{l}\text { UR6 4: Remote } \\
\text { small towns }\end{array}$ & $\begin{array}{l}\text { Settlements of } 3000-10000 \text { people; } \\
>30 \text { min drive to a settlement of } \\
>10000 \text { people }\end{array}$ \\
\hline $\begin{array}{l}\text { UR6 5: Accessible } \\
\text { rural }\end{array}$ & $\begin{array}{l}\text { Settlements of }<3000 \text { people; }<30 \mathrm{~min} \\
\text { drive to a settlement of }>10000 \text { people }\end{array}$ \\
\hline UR6 6: Remote rural & $\begin{array}{l}\text { Settlements of }<3000 \text { people; }>30 \mathrm{~min} \\
\text { drive to a settlement of }>10000 \text { people }\end{array}$ \\
\hline
\end{tabular}

fish, and excluded any items that were processed, tinned, bottled, smoked, salted, breaded or cooked, were selected. Some 'fresh to frozen' items were included if freezing was an essential part of harvesting, as were some fish and vegetable products. These included, for example, frozen prawns and fish fillets, and frozen vegetables such as peas, sweetcorn and carrots. The data set of fresh food products purchased had a total of 577382 entries. Within this data set, 476712 entries (83\%) related to purchases of F\&V and 17065 entries (3\%) related to purchases of fresh fish products.

Household composition within KWP varies by the number of people and their ages; therefore the amount of food needed to be bought each week will also vary. To account for this, expenditure, amount and number of packs of fresh produce were scaled by the estimated energy requirements of the household members to give equivalized values. These were estimated from the sex and age of each individual, and linked to the Dietary Reference Values for Energy ${ }^{(15)}$. The total estimated energy requirement for each household was calculated from the sum of the individual values per household, divided by $10.45 \mathrm{MJ}(2500 \mathrm{kcal})$ to give an adult equivalent value.

Household location was assessed using the Scottish Government's 6-Fold Urban-Rural Classification (UR6 1-6; Table 1). Ninety-five per cent of Scottish geographical areas are defined as rural, housing almost 19\% (13.1\% accessible rural, $5.6 \%$ remote rural) of the population. Based on this, Scotland is classified as a mostly rural country. Annual household income was coded into categories as follows: £0-£9999 (Band 1), £10 000-£19999 (Band 2), £20000-£29999 (Band 3)，£30000-£39999 (Band 4), £40000-£49999 (Band 5), £50 000-£59999 (Band 6), £60 000-£69999 (Band 7) and £70 000 + (Band 8). The SIMD combines twenty-seven indicators across seven domains (income, employment, health, education, skills and training, housing, geographic access and crime). The overall index is a weighted sum of the seven domain scores. The domain weightings used in SIMD 2012, expressed as a 
percentage of the overall weight, are: current income (28\%), employment (28\%), health (14\%), education (14\%), geographic access (9\%), crime (5\%) and housing (2\%). It collects data from 6505 small areas (data zones) that cover Scotland and classifies them as most deprived (ranked 1) to least deprived (ranked 6505). In the current study, households were grouped based on their home postcode into deciles of deprivation, with those least deprived ranked 10. Life stage included: (i) household with no children; (ii) family with children aged 0-4 years; (iii) family with children aged 5-9 years; (iv) family with children aged $10+$ years; (v) family with older dependants; (vi) household where all children had left recently; and (vii) retired people.

Statistical analyses were conducted using the statistical software package IBM SPSS Statistics Version 23.0. ANOVA was used to test for differences in demographic characteristics, expenditure and amounts of foods purchased by urban-rural area classification. Kruskal-Wallis tests were used to compare the distribution of life stage, and income band, across UR6 groupings. Simple linear regression was used to test for associations between expenditure, amounts of foods and number of packs purchased as outcome variables, with urban-rural classification as the predictor variable. Microsoft ${ }^{\circledR}$ Excel 2010 pivot tables were used for descriptive data analysis. In the calculations, the total number of individuals in a household was defined as the number of adults (aged 18 years or above) plus the number of children (aged 17 years or below). Seasons were classified as winter (26 December 2011-25 March 2012), spring (26 March 2012-24 June 2012), summer (25 June 2012-23 September 2012) and autumn (24 September 2012-23 December 2012). Shopping venues were classified into major supermarket brands (ASDA, Co-op, Morrisons, Marks and Spencer, Sainsbury's, Tesco and Waitrose), Internet (major supermarket brands), discount supermarkets (Aldi, Costco, Lidl and Iceland), corner shops and other local shops (Best One, Budgens, Costcutter, FarmFoods, Londis, Mace, Nisa Today, newsagents, off-licence shops, butchers, bakeries, fishmongers, One Stop, Premier Stores, Tesco Metro and Tesco Express, Sainsbury's Local, market stalls and Spar) and other shops (all stores that sell non-food as a main product).

\section{Results}

Most of the reporting households (69\%) were located in urban areas (UR6 1 and UR6 2), while 12\% of households were in small towns (UR6 3 and UR6 4) and 19\% were in rural areas (UR6 5 and UR6 6; Table 2). Ten per cent of reporting households were in remote areas and had to drive for $30 \mathrm{~min}$ or more to a settlement of $>10000$ people. UR6 1 (large urban) had the lowest number of people per household and the lowest number of children per household, whereas UR6 4 (remote small towns) had the highest number of people and children per household.

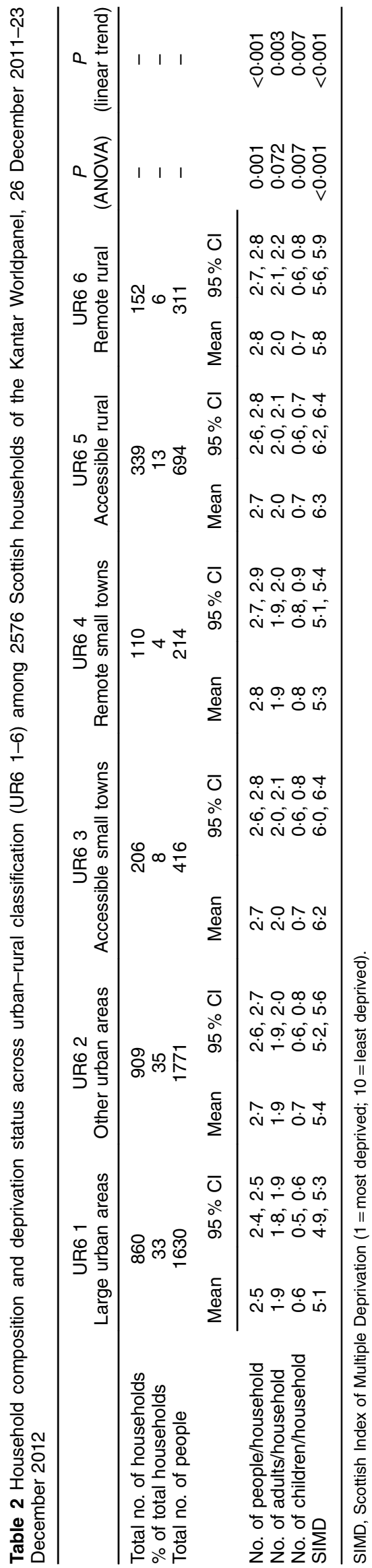


The distribution of life stage was not significantly different across UR6 groups $(P=0 \cdot 169)$ or between urban and rural households $(P=0 \cdot 081)$. There was a higher proportion of households within lower income bands in rural than in more urban areas $(P=0.003)$. On average, households in UR6 3 (accessible small towns) and UR6 5 (accessible rural areas) lived in less deprived areas, whereas households in UR6 1 (large urban) lived in more deprived areas (Table 2).

Across the urban-rural categories from UR6 1 through to UR6 6, there was a significant linear increase in both weekly expenditure (in £) and amounts (in $\mathrm{kg}$ ) of total fresh foods and F\&V bought per adult equivalent (Table 3). Consequently, rural households (UR6 5 or UR6 6) recorded the highest expenditure, and bought the most amounts, of these products. Overall, expenditure on vegetables was approximately $20 \%$ higher than that spent on fruits. Household expenditure on fish, and amount bought, were more variable and did not differ greatly between UR6 categories. This variability probably originates from the fact that not all households purchased fish products; only 68, 66, 68, 65, 73 and $74 \%$ of households reported any fish purchases throughout the year in UR6 1 to UR6 6, respectively. Across UR6 categories, expenditure was highest on oily fish, but in general greater amounts of white fish were purchased, especially in rural households (Table 3).

Mean per adult equivalent weekly expenditure on fresh foods, F\&V and fish differed across the seasons $(P=0.003$, $P<0.001$ and $P=0.011$, respectively), but there was no significant interaction between season and UR6 (Fig. 1). A similar pattern was also seen for the amounts of fresh foods, F\&V and fish bought $(P=0.136, P=0.005$ and $P=0.009$, respectively; Fig. 2). For the amount of fish bought there was a significant interaction between season and UR6 $(P=0 \cdot 036)$.

Expenditure per kilogram and per item were both significantly different $(P<0.001)$ across UR6 categories, and there were significant linear trends for decreasing expenditure per kilogram and increasing expenditure per item from large urban to remote rural areas $(P<0.001)$. The differences were, however, quantitatively small (Table 4).

The majority of fresh food, F\&V and fish purchases were carried out in major supermarkets, even by households in remote rural locations (Table 5). Only the proportions of expenditure through online shopping on fresh foods and F\&V differed significantly by location, with the proportion of expenditure increasing linearly from large urban to remote rural areas $(P<0.001$ for both). Online expenditure was quantitatively small, even by remote rural households.

\section{Discussion}

The main finding of the current study was that households in rural areas (UR6 5 and UR6 6) reported the highest expenditure on fresh foods and $\mathrm{F} \& \mathrm{~V}$, compared with other regions. Purchasing patterns of fish were more variable, mainly due to smaller sample sizes as a consequence of only a subset of consumers buying fish; and therefore no clear differences in fish purchasing patterns between urban and rural areas were found. Overall, these findings are in agreement with those reported by Wrieden et al. ${ }^{(16)}$, who found a higher mean consumption of fresh F\&V, oily and white fish, and fresh potatoes in individuals living in remote small towns/rural/very remote rural areas compared with more urban areas, based on expenditure and food survey data. Similarly, Levin et al. ${ }^{(17)}$ showed that young people from rural areas reported the highest weekly intake of $F \& V$ across Scotland.

Although we found that expenditure on all fresh foods and on F\&V in rural areas (UR6 5 and UR6 6) was higher compared with urban areas (UR6 1-4), this appeared to be a result of purchasing more of these food items, rather than paying more per item. Average prices per pack or average prices per kilogram across fresh food, F\&V and fish purchases were quantitatively similar, although differences were statistically significant across all UR6 categories, with decreasing cost per kilogram in more rural areas (Table 4). This disagrees with findings in some previous studies. Indeed, Dawson et al. ${ }^{(2)}$ found that the cost of a basket of healthy products including fruits, vegetables and fish was highest in rural $v$. urban locations, with costs of $£ 46.68$ and $£ 43.60$ in affluent rural and affluent urban, and $£ 52.75$ and $£ 43.87$ in deprived rural and deprived urban areas, respectively (late 2005/early 2006 prices). The discrepancy may be explained by different foods being bought by urban and rural households in the current study, which did not include a direct likefor-like price comparison. Additionally, Hirsh et al. ${ }^{(1)}$ recently reported that food prices were about $10 \%$ higher in supermarkets in remote rural Scotland and considerably more than this in local stores, although this was in comparison to prices for a rural English town. The latter study also reported that remote rural households mixed supermarket shopping with local top-ups, spending 10-20\% more on a food basket compared with urban British households, while in the most remote island communities, reliance only on local stores could add over $50 \%$ to the total food budget ${ }^{(1)}$. The difference between the current study and some of the older studies may be explained by the fact that most rural households now have easier access to large supermarkets, either directly or through Internet shopping, as supported by the current findings that similar levels of relative spend on fresh food items were reported in rural and urban locations. The growth of online retailing has had a profound effect on island residents in improving access to goods ${ }^{(18)}$, and presumably also had a similar effect on remote rural mainland households. Indeed, 99\% of both rural and urban households in the present study reported at least some expenditure in major supermarket outlets and the percentage of shopping carried out through the Internet was two to three times higher in rural 
Table 3 Average weekly expenditure on fresh* foods, fruits and vegetables (F\&V) and fish, and amount and number of packs of fresh foods, F\&V and fish bought, per adult equivalent, according to urban-rural classification (UR6 1-6), by 2576 Scottish households of the Kantar Worldpanel, 26 December $2011-23$ December 2012

\begin{tabular}{|c|c|c|c|c|c|c|c|c|c|c|c|c|c|c|}
\hline & \multicolumn{2}{|c|}{$\begin{array}{c}\text { UR6 } 1 \\
\text { Large urban } \\
\text { areas }\end{array}$} & \multicolumn{2}{|c|}{$\begin{array}{l}\text { UR6 } 2 \\
\text { Other urban } \\
\text { areas }\end{array}$} & \multicolumn{2}{|c|}{$\begin{array}{c}\text { UR6 } 3 \\
\text { Accessible small } \\
\text { towns }\end{array}$} & \multicolumn{2}{|c|}{$\begin{array}{c}\text { UR6 } 4 \\
\text { Remote small } \\
\text { towns }\end{array}$} & \multicolumn{2}{|c|}{$\begin{array}{l}\text { UR6 } 5 \\
\text { Accessible } \\
\text { rural }\end{array}$} & \multicolumn{2}{|c|}{$\begin{array}{l}\text { UR6 } 6 \\
\text { Remote } \\
\text { rural }\end{array}$} & \multirow{2}{*}{$\begin{array}{c}P \\
\text { (ANOVA) }\end{array}$} & \multirow{2}{*}{$\begin{array}{c}P \text { (linear } \\
\text { trend) }\end{array}$} \\
\hline & Mean & $95 \% \mathrm{Cl}$ & Mean & $95 \% \mathrm{Cl}$ & Mean & $95 \% \mathrm{Cl}$ & Mean & $95 \% \mathrm{Cl}$ & Mean & $95 \% \mathrm{Cl}$ & Mean & $95 \% \mathrm{Cl}$ & & \\
\hline \multicolumn{15}{|l|}{ Fresh foods } \\
\hline Expenditure (£/adult equivalent) & 4.60 & $4.48,4.71$ & 4.33 & $4.22,4.45$ & 4.32 & $4.18,4.45$ & $4 \cdot 24$ & $4.12,4.35$ & 4.78 & $4.62,4.94$ & 4.81 & $4.65,4.98$ & $<0.001$ & $<0.001$ \\
\hline Amount (kg/adult equivalent) & $2 \cdot 1$ & $2 \cdot 1,2 \cdot 2$ & $2 \cdot 1$ & $2 \cdot 1,2 \cdot 2$ & $2 \cdot 1$ & $2,2 \cdot 1$ & $2 \cdot 2$ & $2 \cdot 1,2 \cdot 2$ & $2 \cdot 3$ & $2 \cdot 3,2 \cdot 4$ & $2 \cdot 4$ & $2 \cdot 3,2 \cdot 4$ & $<0.001$ & $<0.001$ \\
\hline No. of packs/adult equivalent & $5 \cdot 0$ & $4 \cdot 9,5 \cdot 1$ & $4 \cdot 6$ & $4 \cdot 4,4 \cdot 7$ & 4.5 & $4 \cdot 4,4.7$ & 4.5 & $4.4,4.7$ & $5 \cdot 0$ & $4 \cdot 9,5 \cdot 2$ & $5 \cdot 0$ & $4 \cdot 9,5 \cdot 2$ & $<0.001$ & 0.003 \\
\hline \multicolumn{15}{|l|}{ F\&V } \\
\hline Expenditure (£/adult equivalent) & 3.25 & $3.17,3.32$ & 3.01 & $2.94,3.08$ & 3.09 & $2.99,3.19$ & 3.09 & $2.99,3.19$ & 3.42 & $3.31,3.53$ & 3.53 & $3.4,3.65$ & $<0.001$ & $<0.001$ \\
\hline Amount (kg/adult equivalent) & 1.8 & $1.8,1.8$ & 1.8 & $1 \cdot 7,1.8$ & 1.8 & $1 \cdot 7,1 \cdot 8$ & 1.8 & $1.8,1.9$ & $2 \cdot 0$ & $1 \cdot 9,2 \cdot 0$ & $2 \cdot 0$ & $2 \cdot 0,2 \cdot 1$ & $<0.001$ & $<0.001$ \\
\hline No. of packs/adult equivalent & $4 \cdot 4$ & $4.4,4.5$ & $4 \cdot 1$ & $4 \cdot 0,4 \cdot 2$ & $4 \cdot 1$ & $3 \cdot 9,4 \cdot 2$ & $4 \cdot 1$ & $4 \cdot 0,4 \cdot 2$ & 4.6 & $4.5,4.7$ & 4.5 & $4 \cdot 4,4 \cdot 7$ & $<0.001$ & $<0.001$ \\
\hline Expenditure on fruit:vegetables & & $1: 1 \cdot 2$ & & $1: 1 \cdot 2$ & & $1: 1 \cdot 2$ & & $1: 1 \cdot 3$ & & $1: 1 \cdot 2$ & & $1: 1 \cdot 2$ & & \\
\hline Amount fruit:vegetables bought & & $1: 1.4$ & & $1: 1.4$ & & $1: 1.5$ & & $1: 1 \cdot 6$ & & $1: 1.5$ & & $1: 1 \cdot 6$ & & \\
\hline \multicolumn{15}{|l|}{ Fish } \\
\hline Expenditure (£/adult equivalent) & 0.33 & $0.31,0.35$ & 0.28 & $0.27,0.30$ & 0.31 & $0.29,0.33$ & 0.23 & $0.21,0.26$ & 0.30 & $0.28,0.32$ & 0.31 & $0.29,0.34$ & $<0.001$ & 0.230 \\
\hline Amount (g/adult equivalent) & 33.1 & $31.4,34.8$ & 28.1 & $26 \cdot 9,29 \cdot 4$ & 31.5 & $29 \cdot 1,33 \cdot 9$ & $24 \cdot 3$ & $21 \cdot 9,26 \cdot 6$ & 31.6 & $29 \cdot 7,33 \cdot 4$ & $31 \cdot 2$ & $28 \cdot 7,33 \cdot 6$ & $<0.001$ & 0.470 \\
\hline No. of packs/adult equivalent & 0.12 & $0.11,0.12$ & 0.09 & $0.09,0.10$ & $0 \cdot 10$ & $0.09,0.11$ & 0.09 & $0.08,0.09$ & 0.10 & $0.09,0.10$ & 0.10 & $0.09,0.11$ & $<0.001$ & 0.020 \\
\hline Expenditure on white fish:oily fish:shellfish:other fish & & $: 10: 4: 1$ & & $0: 13: 7: 1$ & & $3: 13: 7: 1$ & & $1: 16: 10: 1$ & & $: 8: 4: 1$ & & $3: 6: 3: 1$ & & \\
\hline Amount of white fish:oily fish:shellfish:other fish bought & & 7:8:4:1 & & 9:9:5:1 & & 1:11:6:1 & & $2: 10: 7: 1$ & & :5:3:1 & & 3:5:3:1 & & \\
\hline
\end{tabular}

*Some 'fresh to frozen' products were included in the analysis where freezing was considered an essential part of harvesting and where the nutritional quality of these foods is considered similar to the unfrozen equivalent. 

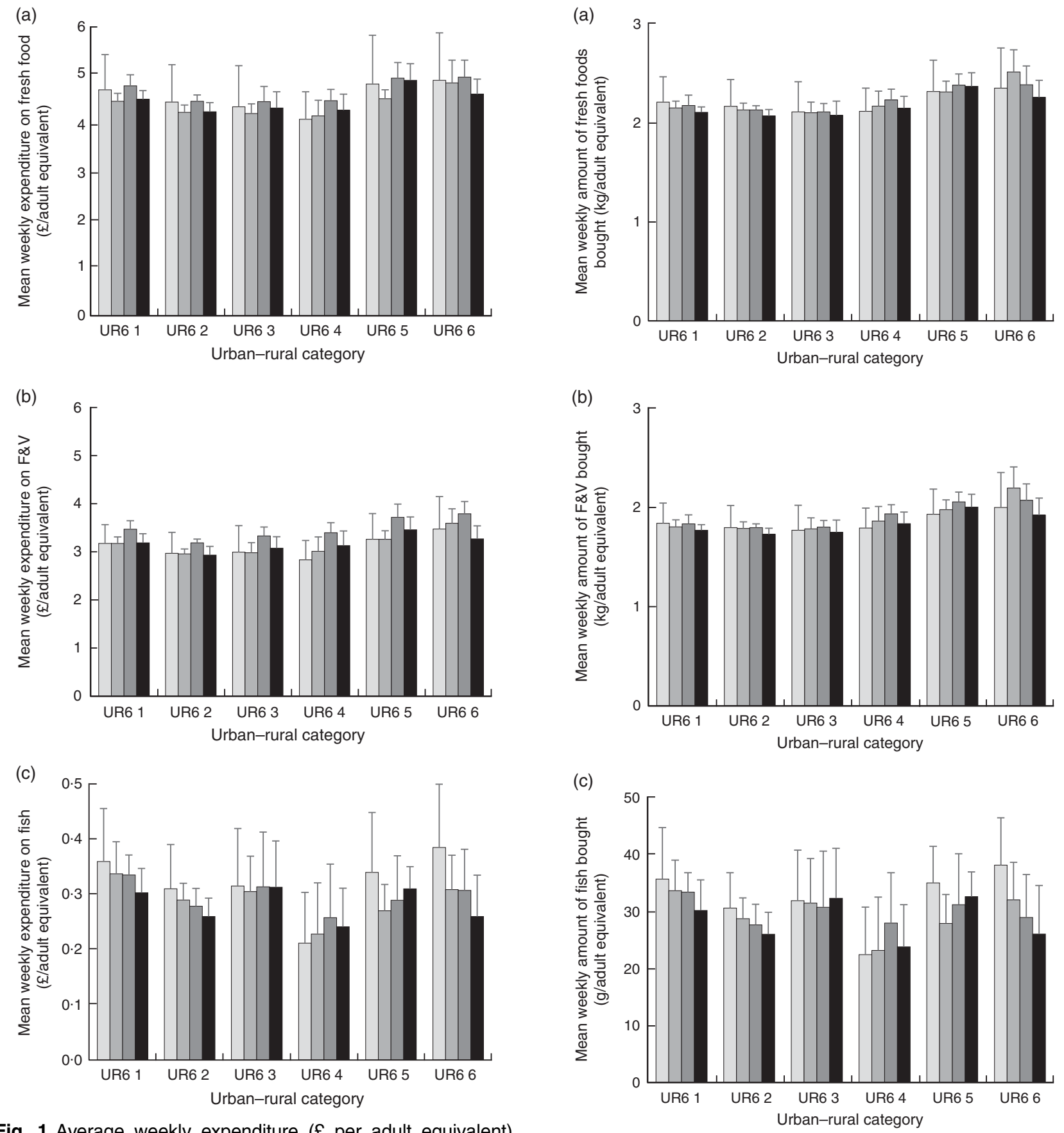

Fig. 1 Average weekly expenditure ( $£$ per adult equivalent) on fresh foods (a), fruits and vegetables (F\&V) (b) and fish (c) during winter ( $\square$ ), spring ( $\square$ ), summer ( $\square$ ) and autumn ( $\square$ ), according to urban-rural classification, by 2576 Scottish households of the Kantar Worldpanel, 26 December 2011-23 December 2012. Values are means with their standard deviations represented by vertical bars (UR6 1-6, Scottish Government's 6-Fold Urban-Rural Classification; see Table 1 for categories)

$v$. urban areas (Table 5). We did find, however, that rural households reported a higher amount of purchases from local shops compared with urban households, but this did not result in major differences in the average price per kilogram of fresh food bought across UR6 categories.

Fig 2 Average weekly amount (kilograms or grams per adult equivalent) of fresh foods (a), fruits and vegetables (F\&V) (b) and fish (c) bought during winter $(\square)$, spring ( $\square$ ), summer ( $\square$ ) and autumn $(\square)$, according to urban-rural classification, by 2576 Scottish households of the Kantar Worldpanel, 26 December 2011-23 December 2012. Values are means with their standard deviations represented by vertical bars (UR6 1-6, Scottish Government's 6-Fold Urban-Rural Classification; see Table 1 for categories)

Both the retail market and food marketing have changed significantly over the last 10 years, with an increasing number of larger supermarkets opening in various locations including out of town, making them readily available to the population, a phenomenon also reported 
by Clarke and Banga ${ }^{(19)}$. This generally leads to greater price competition with lower prices, wider choices and better quality across retail outlets ${ }^{(6,9)}$. Therefore, the current findings provide evidence that differences in spatial access to healthy foods, at least those concerning fresh food purchases, may have become less prevalent throughout Scotland.

We considered expenditure based on season, as availability and price may vary over a year. Indeed, many different fruits and vegetables are harvested at different times of the year ${ }^{(20)}$, but modern storage and transport systems now allow an almost continuous flow of produce throughout the year, at least for products such as apples, onions and lettuce ${ }^{(21)}$. Other items, such as berries, are more readily available and cheaper in season ${ }^{(22)}$. Slightly higher expenditure on all fresh foods and F\&V was evident in summer, across all UR6 categories, and a similar difference was also seen in greater amounts of these foods being bought during summer.

Our data do not explain why, in general, households in rural communities buy more fresh foods compared with those in urban communities. Households in urban areas tend to eat out (e.g. in restaurants or takeaway food) more than do rural households ${ }^{(23)}$, which is not captured in the data used in the current analyses. Therefore, rural households may be more likely to report higher amounts of foods and drinks brought into the home than urban households, even if total consumption is similar. Furthermore, a study by Sayer ${ }^{(24)}$ indicated that an older population in rural areas has a higher consumption of fresh products as well as having more time for cooking, which may contribute towards a higher household expenditure for fresh foods. However, in the current study, the distribution of household life stage was not greatly different in the rural $v$. the other UR6 categories. There may be differences between urban and rural households in the contribution of home-grown fresh food to the diet, although in the UK, in 2012, this together with all other sources of free food (such as gifts) averaged only $2.7 \%$ of all fresh F\&V entering the home. Free eggs contributed $5.0 \%$ of the total amount of eggs ${ }^{(23)}$.

There was a higher proportion of households within lower income bands in rural than more urban areas, yet expenditure on fresh foods and F\&V was higher per person in rural areas. This is in contrast to the observation of Pateman ${ }^{(25)}$ that high-income households residing in rural Britain spent the most on fresh healthy foods, and other studies reporting a positive correlation between higher socio-economic background and highest expenditure on fresh foods ${ }^{(26)}$. However, comparisons between studies should be based on the use of equivalized income values (i.e. household incomes that are adjusted for household size and composition), rather than income bands as used by KWP. Indeed, a higher household income band recorded by KWP does not necessarily mean more money being available per person for buying food. Multiple 
Table 5 Expenditure on fresh ${ }^{\star}$ foods, fruits and vegetables (F\&V) and fish per shop type, according to urban-rural classification (UR6 1-6), by 2576 Scottish households of the Kantar Worldpanel, 26 December 2011-23 December 2012

\begin{tabular}{|c|c|c|c|c|c|c|c|}
\hline & $\begin{array}{c}\text { UR6 } 1 \\
\text { Large urban } \\
\text { areas }\end{array}$ & $\begin{array}{l}\text { UR6 } 2 \\
\text { Other urban } \\
\text { areas }\end{array}$ & $\begin{array}{c}\text { UR6 } 3 \\
\text { Accessible small } \\
\text { towns }\end{array}$ & $\begin{array}{l}\text { UR6 } 4 \\
\text { Remote small } \\
\text { towns }\end{array}$ & $\begin{array}{l}\text { UR6 } 5 \\
\text { Accessible } \\
\text { rural }\end{array}$ & $\begin{array}{l}\text { UR6 } 6 \\
\text { Remote } \\
\text { rural }\end{array}$ & $\begin{array}{c}P \\
\text { (ANOVA) }\end{array}$ \\
\hline \multicolumn{8}{|c|}{ Expenditure on fresh foods per shop type (\% of total) } \\
\hline Major supermarket brands & $80 \cdot 4$ & $76 \cdot 2$ & 73.1 & $77 \cdot 0$ & $75 \cdot 0$ & $74 \cdot 3$ & 0.153 \\
\hline $\begin{array}{l}\text { Internet (major supermarket } \\
\text { brands) }\end{array}$ & 3.5 & 3.8 & $7 \cdot 0$ & $5 \cdot 1$ & $7 \cdot 9$ & $8 \cdot 0$ & 0.001 \\
\hline Discount supermarkets & $11 \cdot 1$ & 13.9 & 13.9 & $12 \cdot 0$ & $12 \cdot 6$ & $11 \cdot 1$ & 0.079 \\
\hline Corner shops/local shops & $4 \cdot 8$ & $5 \cdot 8$ & $5 \cdot 8$ & $5 \cdot 8$ & $4 \cdot 3$ & $6 \cdot 3$ & 0.531 \\
\hline Other shops & 0.3 & 0.2 & 0.3 & 0.2 & 0.2 & 0.2 & 0.269 \\
\hline \multicolumn{8}{|c|}{ Expenditure on F\&V per shop type ( $\%$ of total) } \\
\hline Major supermarket brands & 83.8 & $79 \cdot 0$ & $75 \cdot 2$ & $77 \cdot 1$ & $77 \cdot 9$ & $76 \cdot 4$ & 0.059 \\
\hline $\begin{array}{l}\text { Internet (major supermarket } \\
\text { brands) }\end{array}$ & 3.4 & $4 \cdot 1$ & 6.9 & 4.9 & $7 \cdot 7$ & 8.6 & $<0.001$ \\
\hline Discount supermarkets & $9 \cdot 8$ & $13 \cdot 1$ & $13 \cdot 8$ & 11.9 & $12 \cdot 4$ & $10 \cdot 9$ & 0.127 \\
\hline Corner shops/local shops & 2.9 & 3.7 & 3.9 & $6 \cdot 0$ & 1.9 & 3.9 & 0.250 \\
\hline Greengrocer/fruiterer & 0.4 & 0.3 & 0.7 & $1 \cdot 8$ & 0.7 & 0.2 & $0 \cdot 197$ \\
\hline Other shops & 0.2 & $0 \cdot 1$ & 0.2 & $0 \cdot 1$ & $0 \cdot 1$ & $0 \cdot 1$ & 0.141 \\
\hline \multicolumn{8}{|c|}{ Expenditure on fish per shop type (\% of total) } \\
\hline Major supermarket brands & 78.6 & $73 \cdot 2$ & $69 \cdot 1$ & 73.8 & 74.7 & $68 \cdot 0$ & 0.645 \\
\hline $\begin{array}{l}\text { Internet (major supermarket } \\
\text { brands) }\end{array}$ & $3 \cdot 1$ & $2 \cdot 2$ & $9 \cdot 5$ & $2 \cdot 7$ & $5 \cdot 6$ & $6 \cdot 1$ & $0 \cdot 190$ \\
\hline Discount supermarkets & $9 \cdot 4$ & $12 \cdot 0$ & $9 \cdot 6$ & $17 \cdot 2$ & $10 \cdot 7$ & 10.5 & 0.183 \\
\hline Corner shops/local shops & 8.6 & $12 \cdot 0$ & 11.8 & $6 \cdot 3$ & 8.9 & 14.9 & 0.593 \\
\hline Fishmonger & 3.7 & $7 \cdot 7$ & $9 \cdot 0$ & 3.3 & 5.5 & $12 \cdot 0$ & 0.769 \\
\hline Other shops & 0.3 & 0.5 & 0.1 & 0.1 & 0.1 & 0.4 & 0.751 \\
\hline
\end{tabular}

Major supermarket brands (ASDA, Co-op, Morrisons, Marks and Spencer, Sainsbury's, Tesco and Waitrose), Internet (major supermarket brands), discount supermarkets (Aldi, Costco, Lidl and Iceland), corner shops and other local shops (Best One, Budgens, Costcutter, FarmFoods, Londis, Mace, Nisa Today, newsagents, off-licence shops, butchers, bakeries, fishmongers, One Stop, Premier Stores, Tesco Metro and Tesco Express, Sainsbury's Local, market stalls and Spar) and other shops (all stores that sell non-food as a main product).

*Some 'fresh to frozen' products were included in the analysis where freezing was considered an essential part of harvesting and where the nutritional quality of these foods is considered similar to the unfrozen equivalent.

studies have investigated how deprivation shapes accessibility, availability and affordability of $\mathrm{F} \& \mathrm{~V}^{(27-30)}$. Cummins and Macintyre ${ }^{(31)}$ pioneered research into deprivation and food accessibility in Scotland and since then a growing body of literature has supported the correlation between deprivation and food accessibility ${ }^{(32,33)}$, although some other studies have found the opposite trend, i.e. greater healthy food availability in more deprived areas ${ }^{(28,34)}$. The most recent estimation of food intake from food purchase data in Scotland (2010-2012) ${ }^{(35)}$ shows a clear gradient in F\&V consumption by SIMD quintile: in the most deprived quintile, mean daily consumption was $205 \mathrm{~g} / \mathrm{d}$ compared with $311 \mathrm{~g} / \mathrm{d}$ in the least deprived quintile across 2010 to 2012. Consumption of oil-rich fish was also highest in the least deprived quintile with mean consumption of $39 \cdot 2 \mathrm{~g} /$ week compared with $19.0 \mathrm{~g} /$ week in the most deprived. However, this difference was due to fewer consumers of oilrich fish in the most deprived quintile, rather than lower intakes by consumers ${ }^{(35)}$. Our data indicate that the majority of consumers have access to fresh foods generally, and to F\&V and fish specifically. Therefore, lower purchasing levels may be determined more by food choice (including differences in the amount of food eaten outside the home) and affordability (as lower-income households spend a greater proportion of their income on food than do more affluent households), than by availability and differences in price faced by consumers.

\section{Limitations}

The present study is subject to a number of limitations. The KWP may differ to some extent from the general population as they report lower household incomes, are more likely to be middle-aged and have a greater proportion of multiple-adult households compared with households participating in the Living Costs and Food Survey $^{(36)}$. Also, there is evidence that not all food purchases that are brought into the home are recorded by panel members, with fruit and fish the food groups appearing to be particularly affected, when compared with reporting in the Living Costs and Food Survey ${ }^{(36)}$. Therefore, the amounts of produce reported are likely to be underestimates across the UR6 categories.

\section{Conclusions}

In conclusion, the current study showed that access to, and average price of, fresh foods in general, and of fruits, vegetables and fish in particular, are broadly similar between households living in urban and rural areas. It was 
found that households in rural areas (UR6 5 and UR6 6) spent the most and bought the most amounts of fresh food products, among which are $\mathrm{F} \& \mathrm{~V}$ and fish. Intervention policies to increase consumption of fresh foods should therefore be targeted mostly at large urban areas and accessible small towns (UR6 1 and UR6 3), where the lowest purchases of fresh food products occur.

\section{Acknowledgements}

Financial support: This work was supported by the Scottish Government's Rural and Environment Science and Analytical Services (RESAS) Division. RESAS had no role in the design, analysis or writing of this article. Conflict of interest: The authors declare that they have no conflicts of interest. Kantar Worldpanel had no role in study design or data analysis. Authorship: All authors contributed to the coding of the database. B.d.R., F.B. and S.W. contributed to the analyses in SPSS and Excel. All authors contributed to the writing of the manuscript. Ethics of buman subject participation: Not applicable.

\section{References}

1. Hirsch D, Byran A, Davis A et al. (2013) A Minimum Income Standard for Remote and Rural Scotland. Inverness: Highlands and Islands Enterprise; available at http://www.hie.co.uk/regional-information/economic-reportsand-research/archive/a-minimum-income-standard-for-remoterural-scotland.html

2. Dawson J, Marshall D, Taylor M et al. (2008) Accessing healthy food: availability and price of a healthy food basket in Scotland. J Mark Manage 24, 893-913.

3. Drewnowski A \& Darmon N (2005) Food choices and diet costs: an economic analysis. J Nutr 135, 900-904.

4. Rao M, Afshin A, Singh G et al. (2013) Do healthier foods and diet patterns cost more than less healthy options? A systematic review and meta-analysis. BMJ Open 3, e004277.

5. Maillot M, Darmon N, Vieux F et al. (2007) Low energy density and high nutritional quality are each associated with higher diet costs in French adults. Am J Clin Nutr 86, 690-696.

6. Cummins S, Findlay A, Higgins C et al. (2008) Reducing inequalities in health and diet: findings from a study on the impact of a food retail environment. Environ Plan $\mathbf{4 0}$, 402-422.

7. McEachern MG \& Warnaby G (2005) Food shopping behaviour in Scotland: the influence of relative rurality. Int J Consum Stud 30, 189-201.

8. Scarpello T, Poland F, Lambert N et al. (2009) A qualitative study of the food-related experiences of rural village shop customers. J Hum Nutr Diet 22, 108-115.

9. Cummins S, Findlay A, Petticrew M et al. (2005) Healthy cities: the impact of food retail led regeneration on food access, choice and retail structure. Built Environ 31, 288-301.

10. Micha R, Wallace SK \& Mozaffarian D (2010) Red and processed meat consumption and risk of incident coronary heart disease, stroke, and diabetes mellitus: a systematic review and meta-analysis. Circulation 121, 2271-2283.
11. Rohrmann S, Overvad K, Bueno-de-Mesquita $\mathrm{HB}$ et al. (2013) Meat consumption and mortality - results from the European Prospective Investigation into Cancer and Nutrition. BMC Med 11, 63.

12. Oyebode O, Gordon-Dseagu V, Walker A et al. (2014) Fruit and vegetable consumption and all-cause, cancer and CVD mortality: analysis of Health Survey for England data. J Epidemiol Community Health 68, 856-862.

13. World Cancer Research Fund/American Institute for Cancer Research (2009) Policy and Action for Cancer Prevention. Food, Nutrition, and Physical Activity: A Global Perspective. Washington, DC: AICR; available at http://www.aicr.org/ assets/docs/pdf/reports/Second_Expert_Report.pdf

14. de Roos B, Mavrommatis Y \& Brouwer IA (2009) Longchain $n-3$ polyunsaturated fatty acids: new insights into mechanisms relating to inflammation and coronary heart disease. Br J Pharmacol 158, 413-428.

15. Scientific Advisory Committee on Nutrition (2011) Dietary Reference Values for Energy. London: TSO; available at https://www.gov.uk/government/uploads/system/uploads/ attachment_data/file/339317/SACN_Dietary_Reference_ Values_for_Energy.pdf

16. Wrieden W, Barton KL, Amstrong J et al. (2006) A Review of Food Consumption and Nutrient Intakes from National Surveys in Scotland: Comparison to the Scottish Dietary Targets. Aberdeen: Food Standards Agency Scotland; available at http://www.food.gov.uk/sites/default/files/ multimedia/pdfs/scotdietrytarg.pdf

17. Levin KA, Dundas R, Miller M et al. (2014) Socioeconomic and geographic inequalities in adolescent smoking: a multilevel cross-sectional study of 15 year olds in Scotland. Soc Sci Med 107, 162-170.

18. Freathy P \& Calderwood E (2013) The impact of internet adoption upon the shopping behaviour of island residents. J Retail Consum Serv 20, 111-119.

19. Clarke I \& Banga S (2010) The economic and social role of small stores: a review of UK evidence. Int Rev Retail Distrib Consum Res 20, 187-215.

20. Hospido A, Mila L, McLaren S et al. (2009) The role of seasonality in lettuce consumption: a case study of environmental and social aspects. Int J Life Cycle Assess 14, 381-391.

21. Dolan C \& Humphrey J (2000) Governance and trade in fresh vegetables: the impact of UK supermarkets on the African horticulture industry. J Dev Stud 37, 147-176.

22. Tabart J, Kevers C, Pincemail J et al. (2006) Antioxidant capacity of black currant varies with organ, season, and cultivar. J Agric Food Chem 54, 6271-6276.

23. Department for Environment, Food and Rural Affairs (2014) Family Food 2013. London: DEFRA; available at https://www. gov.uk/government/uploads/system/uploads/attachment_ data/file/385694/familyfood-2013report-11dec14.pdf

24. Sayer L (2005) Gender, time and inequality: trends in women's and men's paid work, unpaid work and free time. Soc Forces 84, 285-303.

25. Pateman $T$ (2011) Rural and urban areas: comparing lives using rural/urban classifications. Reg Trends $\mathbf{4 3}$, issue $1,11-86$.

26. French SA, Wall M \& Mitchell NR (2010) Household income differences in food sources and food items purchased. Int J Behav Nutr Phys Act 7, 77.

27. Ball K, Timperio AF \& Crawford DA (2006) Understanding environmental influences on nutrition and physical activity behaviors: where should we look and what should we count? Int J Behav Nutr Phys Act 3, 33.

28. Black C, Ntani G, Kenny R et al. (2012) Variety and quality of healthy foods differ according to neighbourhood deprivation. Health Place 18, 1292-1299.

29. Winkler E, Turrell G \& Patterson C (2006) Does living in a disadvantaged area mean fewer opportunities to purchase 
fresh fruit and vegetables in the area? Findings from the Brisbane food study. Health Place 12, 306-319.

30. Pearce J, Hiscock R, Blakely T et al. (2008) The contextual effects of neighbourhood access to supermarkets and convenience stores on individual fruit and vegetable consumption. J Epidemiol Community Health 62, 198-201.

31. Cummins S \& Macintyre S (1999) The location of food stores in urban areas: a case study in Glasgow. Br Food J 101, 545-553.

32. Morland K, Wing S \& Diez RA (2002) The contextual effect of the local food environment on residents' diets: the atherosclerosis risk in communities study. Am J Public Health 92, 1761-1767.

33. Shohaimi S, Welch A, Bingham S et al. (2004) Residential area deprivation predicts fruit and vegetable consumption independently of individual educational level and occupational social class: a cross sectional population study in the Norfolk cohort of the European Prospective Investigation into Cancer (EPIC-Norfolk). J Epidemiol Community Health 58, 686-691.

34. Sauveplane-Stirling V, Crichton D, Tessier S et al. (2014) The food retail environment and its use in a deprived, urban area of Scotland. Public Health 128, 360-366.

35. Wrieden W \& Barton KL (2015) Estimation of Food and Nutrient Intakes from Food Purchase Data in Scotland 2001-2012. Aberdeen: Food Standards Scotland; available at http://www.foodstandards.gov.scot/monitoringprogress-towards-scottish-dietary-goals-2001-2012-report-1

36. Office for National Statistics (2015) Living costs and food survey 2014. https://data.gov.uk/dataset/family_spending (accessed July 2016) 